\title{
The benefits of the Biotechnology and
} Biological Sciences Research Council (BBSRC) Diet and Health Research Industry Club (DRINC) to early career researchers working in food, nutrition and human health

Article

Accepted Version

Ferriday, D., Grundy, M. M.-L. and Mills, C. (2018) The benefits of the Biotechnology and Biological Sciences Research Council (BBSRC) Diet and Health Research Industry Club (DRINC) to early career researchers working in food, nutrition and human health. Nutrition Bulletin, 43 (4). pp. 435441. ISSN 1471-9827 doi: https://doi.org/10.1111/nbu.12353 Available at https://centaur.reading.ac.uk/79561/

It is advisable to refer to the publisher's version if you intend to cite from the work. See Guidance on citing.

To link to this article DOI: http://dx.doi.org/10.1111/nbu.12353

Publisher: Wiley-Blackwell 
copyright holders. Terms and conditions for use of this material are defined in the End User Agreement.

\section{www.reading.ac.uk/centaur}

\section{CentAUR}

Central Archive at the University of Reading

Reading's research outputs online 
The benefits of the Biotechnology and Biological Sciences Research Council (BBSRC) Diet and Health Research Industry Club (DRINC) to early career researchers working in food, nutrition and human health

$$
\text { D. Ferriday }{ }^{1} \text {, M.M.-L. Grundy² }{ }^{2} \text {, C. Mills }{ }^{3}
$$

${ }^{1}$ Nutrition and Behaviour Unit, School of Psychological Science, University of Bristol, UK

${ }^{2}$ Animal, Dairy and Food Chain Sciences Group, School of Agriculture Policy \& Development, University of Reading, UK

${ }^{3}$ Department of Food and Nutritional Sciences, School of Chemistry Food \& Pharmacy, University of Reading, UK

*Corresponding author: Dr Myriam M.-L. Grundy, Lecturer, School of Agriculture, Policy and Development, Sustainable Agriculture and Food Systems Division, University of Reading, Reading, RG6 6AR, UK

Email: m.m.grundy@reading.ac.uk

Running title: BBSRC DRINC and early career researchers in diet and human health 


\section{Abstract}

The Biotechnology and Biological Sciences Research Council (BBSRC) Diet and Health Research Industry Club (DRINC) scheme has benefited both academic researchers and members of the food and drink industry. In particular, the Club has given early career researchers (ECRs), working in food, nutrition and human health, the opportunity to work in multidisciplinary projects within a community that has provided support and a training platform for essential transferable skills. After 14 years of success, the DRINC initiative will be coming to an end in 2021. What will come next? How can the next generation of ECRs pursue a career in this research topic without this fantastic opportunity?

Keywords Early career researchers, Scientific progression, Nutrition, Health, Funding, Research Councils 


\section{About the authors}

Dr Danielle Ferriday is a Lecturer in Experimental Psychology in the School of Psychological Science at the University of Bristol, UK. Her research is concerned with the psychology of human dietary behaviour; in particular, the assessment of beliefs about food, episodic memory for food and understanding drivers of food choice and portion size in adults and children. Alongside her PhD research, Danielle worked on a Phase 1 Biotechnology and Biological Sciences Research Council (BBSRC) Diet and Health Research Industry Club (DRINC) project (ref: BB/G005443/1, 'Understanding decisions about portion size: The key to acceptable foods that reduce energy intake?') and for her second postdoc position she was Researcher Co-Investigator on a Phase 2 BBSRC DRINC project (ref: BB/L02554X/1; 'Nudge150: Combining small changes to foods to achieve a sustained decrease in energy intake').

Dr Myriam Grundy is a Lecturer in Agriculture, Food and Nutrition at the University of Reading, UK. She has a background in both biochemistry and nutrition, and her research investigates the effect of plant-based food structures on lipid metabolism. Her PhD (ref: BB/H004866/1 and BB/H531994/1; 'The role of plant cell walls in regulating starch and lipid bioaccessibility from plant foods: in silico, in vitro and in vivo studies') and first postdoc position (ref: BB/L025272/1, 'Impact of food processing on the blood cholesterol-lowering effect of cereal beta-glucan') were funded by the BBSRC DRINC scheme, both of which she performed at King's College London, UK.

Dr Charlotte Mills is a Lecturer in Nutritional Sciences also at the University of Reading, UK. With a background in food science, her research focuses on maximising the cardiometabolic health benefits of plant bioactives using food processing, synergy as well as stratified nutrition approaches. Having completed a BBSRC DRINC funded PhD (ref: BB/G005702/1; 'The impact of cocoa processing on flavanol content absorption and health effects'), Charlotte took 
up a DRINC funded postdoc at King's College London, UK (ref: BB/N020987/1; 'The health impact of industrial interesterification of dietary fats').

\section{Early career researchers in food, nutrition and human health research}

The relationship between food, nutrition and human health is a complex and multifaceted research topic with enormous social and economic impact (BBSRC 2018). Research investigating the interactions between diet and health requires a multi-disciplinary approach, encompassing a wide range of fields, including (but not limited to) food science, crop science, nutrition, engineering, biochemistry, psychology, biology, clinical science and epidemiology (BBSRC, ESRC \& MRC 2015). Collaboration between academia and the food industry is also essential as the food industry contributes significantly to the UK economy (BBSRC, ESRC \& MRC 2015). Academia-industry collaborations allow researchers to gain insights of industry's research challenges, while the industry obtains valuable pre-competitive outputs for developing new products or reformulating existing products (BBSRC 2011).

The primary determinant of research excellence is excellent researchers (Economic Insight 2014). Given the importance of food, nutrition and human health research for public health and for the food industry, there is a need to attract and retain the best and brightest early career researchers (ECRs), so that the future of this pivotal area is secured. Part of early career training should encourage interaction with the food industry to develop understanding of the priorities and the technical and legislative hurdles faced, as well as the opportunities to improve the healthiness of foods, and to provide a foundation to facilitate future research collaboration. In general, in the UK, attracting and retaining talented ECRs is a challenge (Ackers \& Gill 2005) and this is particularly the case for ECRs with science, technology, engineering and mathematics (STEM) skills (UKCES 2013). Furthermore, it is unclear what impact Brexit in 2019 will have on ECR funding opportunities and immigration from the European Union (EU) (Galsworthy \& McKee 2017). Globally, it is acknowledged that it is more difficult to attract and retain talented female ECRs (Larivière et al. 2013). 
In a recent review of nutrition and human health research, succession planning and career progression was highlighted as a critical area (MRC, NIHR \& OSCHR 2017). Specifically, the document highlights that the field is 'approaching a critical point as a cadre of nutrition researchers move towards retirement and new excellent researchers are not entering the field in sufficient numbers due to perceived poor career progression and the challenges of undertaking high quality nutrition research' (p39) (MRC, NIHR \& OSCHR 2017). The barriers highlighted in this review were: i) perceived lack of opportunity, including fellowships, for the career development and progression of outstanding senior post-doctoral researchers; ii) a general lack of appropriate mentoring; iii) the absence of standardised training to foster the next generation of researchers well positioned to undertake high quality integrative nutrition research; and iv) the perception that research careers in the food industry are not an attractive option (MRC, NIHR \& OSCHR 2017). The purpose of this article is to highlight the benefits of BBSRC DRINC for ECRs in food, nutrition and human health research, and to explore the possibilities for a future after the DRINC initiative has ended.

\section{What is BBSRC DRINC?}

The DRINC programme was established in 2007 to support pre-competitive research investigating the link between diet and health (Hanley et al. 2015). It is a cross-council programme led by the BBSRC in partnership with the Medical Research Council (MRC) and the Engineering and Physical Sciences Research Council (EPSRC). Funding for projects was provided by these three research councils ( $£ 20$ million) and from a consortium of companies ( 2 million). Research priorities matched the BBSRC's strategic research priorities and linked to the MRC and the EPSRC strategic priorities.

DRINC has funded a broad array of research projects linking diet and health. In addition to advancing understanding of how diet and food components influence human health, the Club provides the food industry with the latest evidence to facilitate the development of healthier food products. Project grants have been awarded using the same processes as used for fully public funded research. DRINC has a Steering Group comprising 
both industrial and academic experts to guide the strategic direction of the programme and to monitor ongoing projects. The Knowledge Transfer Network (KTN) are the external coordinators for the programme.

The first phase of DRINC (three funding rounds in 2008, 2009 and 2010) had 15 food/beverage company members, and distributed around $£ 12$ million, funding 25 research projects and 30 studentships at 26 centres (DRINC 2018). These projects were multidisciplinary and involved scientists from nutrition to social sciences, to agriculture and physics, as well as members of the UK food and drink industry. In 2011, a review panel of experts evaluated the outputs and impact of the first phase of DRINC and concluded that the initiative was an effective scheme for promoting high quality interaction between academia and the food industry (BBSRC 2011), and the success has continued. For example, in March 2015, Professor lan Givens at the University of Reading was awarded 'BBSRC Innovator of the Year' based on his work reducing the saturated fat content of milk (Givens 2017), which has been adopted by Marks and Spencer for their own main brand of milk. Professor Givens commented 'much of my research in this area has been supported by BBSRC DRINC which is an excellent model for integrating research with industry' (University of Reading 2015). For further examples of projects that have delivered useful outputs and created significant industrial impact, see the case studies in 'DRINC - A recipe for success' (BBSRC 2012).

Following its initial success, a second phase of DRINC was launched in November 2012 (Hanley et al. 2015). In total, 43 projects and 30 studentships have been funded by DRINC, involving 34 research organisations and 14 industry partners. Thus, DRINC, through the networking and dissemination opportunities that accompany its funding awards, has built a community composed of scientists at various stages of their career, food industry members and other stakeholders, such as the KTN.

How did DRINC support ECR career progression in food, nutrition and human health research? 
PhD training

The first phase of BBSRC's DRINC initiative funded $30 \mathrm{PhD}$ studentships at 26 centres (BBSRC 2011). Unfortunately, funding for PhD students was not continued for the second phase of DRINC. This truly interdisciplinary training provided a fantastic opportunity for students to gain a unique insight into the challenges that the food and drink industry face and the research needed to address these issues; thereby preparing students for a career in food innovation to meet consumer and industry requirements. Indeed, the evaluation of DRINC Phase 1 praised the process, observing that 'The training provided through DRINC is likely to have a positive impact on the recruitment of skilled scientists by industry' and that 'There is potential for greater interaction between industry members and post-doctoral researchers/PhD students' (p.5) (BBSRC 2011).

DRINC has held dissemination meetings every 6 or 9 months (see further details about these meetings in the 'Communicative Platform' section below). This has meant that DRINCfunded PhD students have had the opportunity to present their work regularly in front of an audience of both academics and food industry experts. This has allowed them to build their confidence in networking and to improve their oral presentation skills in a familiar and friendly environment.

Some of the PhD students, including two of the authors of this article, were also involved in the second phase of DRINC as postdoctoral researchers. Having PhDs funded during the initial phase enabled these ECRs to create strong collaborations that could be developed into another project at a crucial stage of their career.

\section{Supporting early career researchers of all levels}

BBSRC DRINC serves as a platform to develop the careers of ECRs in the broad remit of diet and health, encompassing both researchers funded directly by DRINC as well as those on the periphery. It has proven to benefit the career trajectories of a wide variety of ECRs from interns who spent a few months working on projects to research assistants, PhD students and postdoctoral research associates who were more heavily involved. Feedback from ECRs 
involved in DRINC has been overwhelmingly positive and the scheme has opened doors for many.

There seems to have been clear benefit from involvement in DRINC in supporting researchers to secure $\mathrm{PhD}$ funding. Eugenia Romano worked on a DRINC project (ref: BB/L02554X/1; 'Nudge150: Combining small changes to foods to achieve a sustained decrease in energy intake') during a research placement at the University of Bristol and commented that 'The collaborative and competent environment (within DRINC) played a great role in strengthening my research skills and my confidence as a future researcher, helping me to obtain my current position as a PhD student in the Appetite and Obesity research group at the University of Liverpool'. Duncan McCaig a research assistant on a DRINC project (ref: BB/L02554X/1; 'Nudge150: Combining small changes to foods to achieve a sustained decrease in energy intake') at the University of Bristol is also grateful to the scheme, noting that it 'Helped me develop confidence as a researcher working with a variety of methodologies, as well as helping me to develop a clearer understanding of my own research interests. I am now midway through a PhD at Warwick University relating to eating disorders, and have adopted a mixed-methods approach that builds on the foundation of my experience'. Dr Sophie Castle gained experience working on a BBSRC DRINC funded project (ref: BB/G005702/1; 'The impact of cocoa processing on flavanol content absorption and health effects') at the University of Reading during her Master's degree, she noted 'The experience that I gained working on the coffee project was pivotal in helping me secure my BBSRC-CASE PhD studentship'; indeed, the studentship she obtained was borne out of the DRINC project and with support from a DRINC industry member.

Beyond the examples above, PhD studentships were integrated within the first phase of DRINC, and the success stories therein are plentiful. Christina Potter who took up a research position at the University of Oxford after being involved in a DRINC project (ref: BB/L02554X/1; 'Nudge150: Combining small changes to foods to achieve a sustained decrease in energy intake') at University of Bristol during her PhD said 'After finishing my PhD, I was hired to work for 4 years as a postdoctoral researcher. Due to my experience, I have 
been given the freedom to independently develop and run a series of studies in the first 6 months of employment'. Cathrina Edwards undertook a PhD at King's College London funded through DRINC phase 1 (ref: BB/H004866/1; 'The role of plant cell walls in regulating starch and lipid bioaccessibility from plant foods: in silico, in vitro and in vivo studies') and is now a Principle Investigator at the Quadram Institute Bioscience. She explained how being a part of the initiative helped shape her career, noting 'The direction of my research has been strongly influenced by the findings of my PhD projects and interactions with the food industry and DRINC. DRINC played an important role in shaping my strategic research vision, which was critical for securing my current role as a Research Leader'. Louise Wilson completed a DRINCfunded PhD at the University of Surrey [ref: BB/I006192/1; 'Ergocalciferol (D2) vs. cholecalciferol (D3) food fortification: Comparative efficiency in raising $250 H D$ status and mechanisms of action (D2-D3 Study)'] before working at Yakult UK Ltd. She comments that 'Being a BBSRC DRINC PhD student provided me with an opportunity to collaborate with industry at an early stage of my nutrition career, which proved invaluable in gaining my current role in the food industry. Furthermore, the regular DRINC meetings gave me the opportunity to develop key networking skills, resulting in gaining a community of passionate nutrition experts that I now get the opportunity to work with".

DRINC-funded projects have also supported many post-doctoral researchers and aided their career development. Involvement in these projects has benefitted those pursuing a career in academia (e.g. the three authors of this article) and also those transitioning to a career working in the food industry.

Involving ECRs at all career stages in the DRINC programme not only benefited the researchers but projects also thrived as a result of the ECR's enthusiasm and fresh way of thinking.

Multidisciplinary/ 'integrative' approach to diet and health research Interdisciplinary nutrition research and effective collaborations are key to undertaking meaningful, worthwhile research with the aim of improving global health (MRC, NIHR \& 
OSCHR 2017). The aim of the DRINC programme has been to fund academia-industry collaborative research projects; all projects within DRINC involve more than one institution working together and all projects benefitted from industrial input at the regular dissemination events (see section below) and through the Steering Group. This approach has allowed ECRs to acquire novel combinations of a range of skills and competencies, which cross over many fields in not only nutrition and food science but also agriculture, social sciences, biochemistry and human physiology. This wealth of knowledge and expertise provided ECRs with a clear advantage for pursuing a career in research in either academia or industry. This feature of DRINC is also shared by more senior members of the community as supported by Professor Euston's testimony from Heriot-Watt University (ref: BB/M027597/1; 'Edible oleogels for reduction of saturated fat'): 'Receiving funding from DRINC and being able to meet members of the DRINC community has allowed me to expand my network of contacts and collaborators. The opportunity to talk with food industry representatives, and to understand the often differing priorities of academic and industrial research is highly beneficial to both the academics and research associates who work on the project'.

The DRINC programme has allowed academics and members of the food industry to meet regularly and build strong relationships. These relationships have formed the foundation of new research collaborations, which may not have otherwise been formed. These cross disciplinary collaborations have stimulated successful follow-on funding applications and have frequently included industrial partnerships facilitated by DRINC. Indeed, grant holders have secured further funding from sources including BBSRC Follow on Funding, Industrial CASE Studentships, Industrial Partnership Awards, stand-alone BBSRC LINK grants, Innovate UK funding such as Knowledge Transfer Partnerships, SMART awards and EU Horizon 2020 initiatives (Hanley et al. 2015). These newly generated research projects have benefited ECRs outside of the direct remit of the DRINC (i.e. by opening up new job opportunities) as well as those already embedded within the DRINC community, by providing opportunity for ECRs to be involved with the research proposal applications. Involvement in this process and inclusion as a named researcher or, even better, as researcher co-investigator is a strong advantage 
when applying for tenured or academic positions. Indeed, for career progression, it is essential to demonstrate the capability to secure funding.

\section{Communicative platform}

A key highlight of DRINC community membership is the regular dissemination events. These events are held at various locations around the UK and are attended by the DRINC stakeholders, including the industrial partners and those working on current DRINC funded projects. Lasting around 2 days, they provide opportunities for exclusive access to updates from the DRINC research projects, to catch-up with current collaborators, and to form new collaborations. These have proved invaluable by facilitating the formation of an ECR support network, helping to raise ECR's scientific profile and engaging ECRs with future research partners. The dissemination events provide a stimulating environment and allow ECRs access to senior academics and established industrial partners from across the board. Indeed, the events always allow ample time to discuss future research plans.

At recent events, the ECRs have been invited to present their work in the form of a very brief 'flash' oral presentation as well as presenting a poster, no matter what stage the project is at, which provides an inclusive environment and gives ECRs a genuine presence at the events. The events are also an opportunity to gain an understanding of the latest research funding calls, which is extremely beneficial for those at the start of their career.

A key benefit of the DRINC dissemination events is that they bring together multiple food industry companies in a research forum, working in a unified, rather than competitive manner. These meetings facilitate open dialogue and give ECRs the opportunity to gain an understanding of the needs and priorities of the food industry, and allow the food industry to learn about the research capabilities of the academic members.

Outside of the dissemination events, travel funds budgeted into the DRINC projects have allowed ECRs to attend conferences to network and disseminate results. The BBSRC has been a central player in relaying the success of the DRINC programme to the wider 
research community; the successes of ECRs are highlighted in the 'Recipe for success' case study reports (BBSRC 2012).

\section{Public facing}

Many successful DRINC funded projects involved public engagement activities. This provided ECRs with unique opportunities to broaden their skills in science communication outside the academic setting, to raise the profile of the scientific community and food industry, and to receive input from lay audiences about their research. Not only does this enhance the communication skills of the ECRs but it also helps to demonstrate the 'real-world' impact of their research, an area that can be overlooked by ECRs who tend to work on short fixed-term contracts and are not involved in the writing of the original research proposal. It also encourages ECRs to take ownership of the research and reinforces the importance of relaying research projects and results in a responsible manner to the general public, which is becoming ever important. A broad array of engagement activities has been generated as a result of DRINC grants, which have in many cases expanded ECRs' network. Examples of engagement activities have included work with the British Nutrition Foundation, artists, the media, including television appearances (e.g. 'Food Unwrapped' on Channel 4), schools and other bodies, such as Food Matters Live.

\section{What next?}

The final set of DRINC-funded projects will end by 2021 with no sign of funding for a third phase. So where does this leave the future of ECRs in the field of food, nutrition and health? The DRINC initiative has been a very positive and beneficial experience that has facilitated the training of future academic and industrial scientists. A platform to continue a research dialogue between all DRINC members (past and present) would be welcomed by ECRs as a means of maintaining the support network developed whilst in the early stages of their careers.

At a time of job insecurity, specifically with ECRs working on sometimes very short, fixed-term contracts, supportive initiatives would certainly be welcomed by ECRs. Providing a 
means for ECRs to continue to train and grow will benefit both the researchers themselves and the future of UK diet and health research. Future initiatives in this area should address the perceived lack of opportunity, particularly for outstanding senior post-doctoral researchers, lack of appropriate mentoring, absence of standardised training and the perception that research careers in the food industry are not an attractive option (MRC, NIHR \& OSCHR 2017).

The BBSRC Research in Food Nutrition and Health: Strategic Framework 2015-2020 is appreciated but does not address the gap that DRINC will leave (BBSRC 2014). The MRC'S priorities for nutrition research are noted favourably by the authors and the recent initiative for funding research in the field of diet and health, namely the UK Nutrition Research Partnership Collaborative Awards, is also a positive step. The MRC's Office for Strategic Coordination of Health Research (OSCHR) review highlighted the need to include all stakeholders in future human nutrition research, specifically the food industry, and describes the need to establish strong pre-competitive research collaborations, which is a valid recommendation (Buttriss 2018). For ECRs, securing and developing these collaborations typically requires support from more senior colleagues, such as that given through DRINC. There is a distinct difference in the remit of MRC funding compared to BBSRC or EPSRC, and one of the key reasons for the success of DRINC was that it encompassed a fully cross-council approach, where mechanistic research was included alongside more applied research; this approach would be favourable for the future of health research and ECRs.

All UK Research Councils provide ECR funding streams, such as fellowships. However, these are very competitive and programmes like DRINC provide the support and mentoring to help ECRs strengthen their applications. To obtain a research grant in a competitive environment as an independent researcher, ECRs need to be mentored by more senior colleagues and DRINC started to make this common place but senior researchers need more encouragement and resources to support those who are fighting for an independent research career. Encouraging Principle Investigators to name ECRs as postdoctoral researchers or Co-Investigators on grant applications would greatly benefit ECRs. Providing 
pump-priming funding would also be beneficial by allowing ECRs to generate preliminary data to support grant applications, as well as encouraging Principle Investigators to cost time into grants for career progression of their junior researchers. A bright future for food, nutrition and human health research relies on giving ECRs the tools and opportunities to face the challenges of establishing careers in this field. Providing platforms to build communities with peers, access to industry-facing pre-competitive forums and opportunities to obtain competitive research grants would certainly set ECRs in good stead for a successful research career.

\section{Conflict of interest}

The authors have received funding from BBSRC DRINC prior to the writing of this manuscript but they received no financial contribution towards the production of this particular article. 


\section{References}

Ackers L \& Gill B (2005). Attracting and Retaining 'Early Career' Researchers in English Higher Education Institutions. Innovation 18: 277-299.

BBSRC (Biotechnology and Biological Sciences Research Council) (2011) Diet And Health Research Industry Club (DRINC) Working Group Report. Available at https://bbsrc.ukri.org/documents/drinc-2011-evaluation-report-pdf/ (accessed 20 August 2018).

BBSRC (Biotechnology and Biological Sciences Research Council) (2012) Diet And Health Research Industry Club (DRINC) - A recipe for success. Available at https://bbsrc.ukri.org/documents/drinc-recipe-for-success-pdf/ (accessed 20 August 2018).

BBSRC (Biotechnology and Biological Sciences Research Council) (2014) Research in Food, Nutrition and Health. Strategic Framework: 2015 - 2020. Available at https://bbsrc.ukri.org/documents/1503-fnh-strategic-framework/ (accessed 22 August 2018)

BBSRC (Biotechnology and Biological Sciences Research Council) (2018) Food, nutrition and health. Available at https://bbsrc.ukri.org/funding/grants/priorities/food-nutrition-andhealth/ (accessed 14 August 2018)

BBSRC DRINC (Biotechnology and Biological Sciences Research Council Diet And Health Research Industry Club) (2018) Management of the Diet and Health Research Industry Club (DRINC). Available at https://bbsrc.ukri.org/documents/drincmanagement/ (accessed 20 August 2018)

BBSRC, ESRC \& MRC (Biotechnology and Biological Sciences Research Council, Economic and Social Research Council \& Medical Research Council) (2015) Cross-Council vision for Food, Nutrition and Health research. Available at https://mrc.ukri.org/documents/pdf/cross-council-fnh-bk-26-march-2015/ (accessed 17 August 2018).

Buttriss J L (2018) The Office for Strategic Coordination of Health Research (OSCHR) Review of Nutrition and Health Research: Window of opportunity. Nutrition Bulletin 43:79-84.

DRINC (Diet And Health Research Industry Club) (2018) Executive Summary - Diet and Health Research Industry Club (DRINC). Available at https://bbsrc.ukri.org/documents/drinc-executive-summary/ (accessed 17 August 2018).

Economic Insight (2014) Growing the best and brightest; The drivers of research excellence. Available https://assets.publishing.service.gov.uk/government/uploads/system/uploads/attachm ent data/file/298507/Growing the Best and Brightest. The Drivers of Research Excellence.pdf (accessed 17 August 2018).

Galsworthy M \& McKee M (2017) A plan for U.K. science after the European Union referendum. Science 355: 31-32.

Givens D I (2017) Saturated fats, dairy foods and health: A curious paradox? Nutrition Bulletin 42:274-282.

Hanley B, Broadway S \& Brookman J (2015) The BBSRC DRINC programme - Precompetitive research and industry partnernships in diet and health. Nutrition Bulletin 40: 130-133.

Larivière V, Ni C, Gingras Y et al. (2013) Global gender disparities in science. Nature 504: 211-213.

MRC, NIHR \& OSCHR (Medical research Council, National Institute for Health Research \& Office for Strategic Coordination of Health Research) (2017) Review of Nutrition and Human Health Research. Available from https://mrc.ukri.org/documents/pdf/review-ofnutrition-and-human-health/ (accessed 17 August 2018). 
UKCES (UK Commission for Employment and Skills) ( (2013) The Supply of and Demand for High-Level STEM Skills. Available at https://assets.publishing.service.gov.uk/government/uploads/system/uploads/attachm ent data/file/302969/high-level-stem-skills-exec-summary-full.pdf $\quad$ (accessed 20 August 2018).

University of Reading (2015) Professor lan Givens wins BBSRC 'Innovator of the Year' award. Available at https://www.reading.ac.uk/news-and-events/releases/PR629366.aspx (accessed 20 August 2018). 